\title{
IMPACT OF DENTIN CONDITIONING ON SHEAR BOND STRENGTH OF SELF-ADHESIVE RESIN CEMENT
}

\author{
Shaimaa Ahmed Abo El-Farag Ibraheim*
}

\begin{abstract}
Statement of the Problem: The clinical success of fixed dental prosthesis depends on the bond strength between the prepared tooth and the luting cement.

Purpose: To estimate the bond strength of self-adhesive resin cement to dentin of prepared teeth using different conditioning methods.

Materials and Methods: Mandibular first molars $(n=32)$ periodontally compromised and indicated for extraction were collected after patient consent from oral surgery department, Faculty of Dentistry, Mansoura University. Flat dentin surfaces were prepared and treated as follows: (1) no pretreatment of dentin (T-NT) control group; (2) self-etching bonding agent (T-SEB); (3) Dentin conditioning agent (polyacrylic acid) (T-PA) (4) Ethylenediaminetetraacetic acid (EDTA) (TED). Self-adhesive resin cement (SuperCem), was used to lute discs of composite on conditioned prepared teeth surfaces. Specimens were stored in distilled water at $37^{\circ} \mathrm{C}$ for 24 hours after that thermal cycling was performed between $5^{\circ} \mathrm{C}$ and $50^{\circ} \mathrm{C}$ in distilled water with a dwell time of 1 minute (Theromocycler, Robota, Alexandria, Egypt) for 10.000 cycles. Shear bond strength (SBS) was measured in MPa using a universal testing machine at a crosshead speed of $0.5 \mathrm{~mm} / \mathrm{min}$. Scanning electron microscope (SEM) was used for failure modes examination.
\end{abstract}

Results: SPSS (22) was used for statistical analysis. One-way ANOVA and Tukey tests were used for comparing data at $(\mathrm{p}=0.001)$. The highest mean SBS (MPa) was reported for group T-SEB (3.9 MPa), while the lowest mean SBS value was observed for group T-NT (2 MPa). There was no statistically significant difference between group T-SEB (3.9 MPa) and group T-PA (3.3 MPa). Also there was no statistically significant difference between the other two test groups (T-NT=2 MPa, $\mathrm{T}-\mathrm{ED}=2.6 \mathrm{MPa})(\mathrm{P}>0.05)$. On the other hand there was statistically significant difference between group T-NT (2 MPa) and groups T-SE and T-PA groups $(\mathrm{P}<0.05)$.

Conclusion: Conditioning of prepared dentin using self-etching adhesive or polyacrylic acid significantly increased the bond strength of self-adhesive resin cement.

KEY WORDS: conditioning materials, adhesive resin cement, composite discs, bond strength.

* Lecturer at Department of Fixed Prosthodontics, Faculty of Dentistry, Mansoura University, Egypt 


\section{INTRODUCTION}

The success and immortality of any indirect fabricated restorations are affected by many factors which must be taken into consideration, these factors can be summarized as preparation design/ coarseness, provisional luting agent, methods of cleansing, adaptation of the permanent restoration, finally used definitive cementing agent. ${ }^{1}$ Resinbased dental luting cements play an important role in cementation technique as it can infiltrates into the dentinal tubules and exposed collagen network to stimulate a micromechanical interlock. ${ }^{2,3}$

Resin luting cements have many advantages such as: wide variable shades simulating natural tooth appearance, minimal solubility in oral environment, biocompatibility to soft tissues, and strengthening effects to the remaining dental structure. ${ }^{4}$ Therefore the use of these cements has been increased over the past decade, However the main disadvantage of the adhesive cementation technique is the number of steps involved during the luting procedure. For longer than 20 years, conventional resin cements have been used combined with dentin bonding agents; this has resulted in additional number of steps during cementation procedure that is considered time-consuming and technique-sensitive. ${ }^{5}$

Also, the variation between the degree of penetration of acid etching and resin infiltration can lead to postoperative sensitivity and hydrolytic degradation because of the large area of collagen fibrils remain exposed but not encapsulated by the bonding resin. ${ }^{6}$ The presence of self-adhesive resin cements in the world of dentistry was a major development in dental adhesive cementation early in the decade, because they do not consume additional steps of etching, priming, or bonding; instead, their implementation is performed simply by a single clinical step, which permits the clinician to perform a cementation technique similar to that used with any other types of conventional luting agents such as zinc-phosphate and polycarboxylate luting agents. Self-adhesive resin cements, known as pastiness composed of filled polymers added for enhancement its adhesion to tooth structure without the presence of any additive materials as adhesive or etchant, these materials were introduced to dentistry within the past decade and have acquired very fast in dental field. ${ }^{7}$

Self-adhesive cements also defined as a crossbred materials that collect properties of colored restoratives as composite, self-etching adhesives and, in some cases, dental luting agents. The development of dimethacrylate monomers specifically to be utilized in resin-based composites, was improved by Bowen. The newly produced self-adhesive resin cements are composed of twomaterials which changed to its final form by: either manual manipulation, trituration of capsule or produced through an auto-mixing dispenser. ${ }^{7}$

Resin cements must be characterized by high bond strength to a diversity of variable substrates, including hard dental tissues, esthetic tooth colored restorative materials as porcelain and ceramics, non-esthetic materials as gold and metal alloys, and laboratory fabricated composite resin. It was produced essentially to interact with the dentin substrate without excessive surface elaboration. While historically, effective phosphoric acid etching technique was used to enhance bonding to enamel surface, these recent cements use another modified component that may not produce equivalent micromechanical type of etching for bonding. ${ }^{7}$

Many studies explained the impact of these cements on the smear layer and they concluded that self-adhesive cements react with superficial layer of dentin, causing incomplete demineralization of the smear layer and the formation of short resin tags. ${ }^{\mathbf{8}, 10}$ Weak bonding mechanism and poor adhesive interfaces are the results of an incompletely demineralized/infiltrated smear layer which formed with area of adhesion.11

In the last decades, the self-adhesive resin cements became more prevalent and favorable type 
of cementation material. Their progress produced several material types that differ mainly in the technique of application, and in their chemical compositon. ${ }^{12}$ On the other hand, there are many essential factors should be studied well during selection of the proper cementation material for each clinical situation, these factors include: mild acidity of self-etch adhesive systems, the effective composition of acidic monomers, dual cure setting mechanism, and neutralization of the initial low $\mathrm{pH}$ of the cement by its fillers content. ${ }^{13}$ Adhesive systems characterized by acid monomers that help in removal of the smear layer partially, leading to micropores creation and enhanced retention to the prepared tooth surface micro-mechanically. In addition to previously mentioned, there is a chemical reaction between phosphoric acid monomers and hydroxyapatite crystals of prepared tooth structure. Easiness of its application is a major benefit, as well as reduced postoperative sensitivity, and increased its ability for moisture tolerance. ${ }^{7}$ The bonding mechanism of resin cements, can be adversely affected by presence of a smear layer which is considered a factor that can compromises the clinical bonding efficiency of a permanent restoration. ${ }^{14}$ For self-etching self-adhesive cements, no need for surface pretreatment before cementation to remove the smear layer which formed during tooth preparation. Therewith, many studies reported that using of different materials will activate the interaction between applied resin cement and dental tissues that will be followed by increasing the bond strength., ${ }^{2,15}$

The planning to obtain strong bond has changed and developed highly in the last decades. ${ }^{16}$ Methods used for preparation and finishing of dentin surface are considered an effective part in the strength of bond, stability and accuracy of this bond..$^{17}$ It was found that using of concentrated phosphoric acid for dentin treatment before cementation by self-adhesive resin cement, was ineffective or harmfull. ${ }^{2,18}$ So, other acidic agents such as EDTA and polyacrylic acid were developed to be used., $9,18,19$

These conditioning agents stimulate partial elimination of the smear layer only without any change in the mineral phase of the dentin, which improves the chemical interaction between the cement layer and the substrate. Removal of the smear layer using polyacrylic acid performed safely without significantly etching the dentin. ${ }^{9}$ The most of self-adhesive cements composed of functional methacrylated phosphoric ester monomers and there is no sufficient knowledge about their chemical interaction with hydroxyapatite. ${ }^{20}$ Many other factors showed effect of these cements on adhesion, such as the chemical composition and physical characteristics (Wetting) of the cement. ${ }^{21}$ However, no adequate studies have been performed to confirm the effectiveness of these treatments on the bonding of self-adhesive cements to exposed dentin. Using of different conditioning materials for treatment of the dentin surface has shown various results on the smear layer. Their effects range from simple to complete or partial removal of the smear layer, activating the process of demineralization that can stimulate interaction between the resin and the collagen network on the dentin surface. ${ }^{4}$

The purpose of this in vitro study concentrated on the shear bond strength of self-adhesive resin cement to dentin, and impact of different dentin conditioning systems on the shear bond strength. The present research work performed under the null hypothesis that there is no difference in shear bond strength to dentin when different conditioning agents are used, as well as that the polyacrylic acid application does not promote the shear bond strength of self-adhesive resin cement to prepared tooth surface.

\section{MATERIALS AND METHODS}

Materials used in this study and their composition are shown in (Table 1). 
TABLE (1). Materials utilized in this study

\begin{tabular}{|c|c|c|c|}
\hline Materials & Lot/Batch No & Compositions & Manufacturer \\
\hline $\begin{array}{l}\text { SuperCem, Self-Etch Self- } \\
\text { Adhesive Resin Cement }\end{array}$ & 3018001 & $\begin{array}{l}\text { Base: silicon dioxide, Barium glass, Bis-GMA, } \\
\text { Triethyleneglycol Dimethacrylate, Diurethan- } \\
\text { dimethacrylate. } \\
\text { Catalyst: silicon dioxide, Barium glass, } \\
\text { Triethyleneglycol Dimethacrylate, Diurethan- } \\
\text { dimethacrylate, Champhorquione }\end{array}$ & $\begin{array}{l}\text { DentKist, Inc, Eli- } \\
\text { Dent group S.P.A. } \\
\text { KOREA. }\end{array}$ \\
\hline $\begin{array}{l}\text { Kerr, OptiBond ALL-IN- } \\
\text { ONE. Self-Etch Dental } \\
\text { Adhesive }\end{array}$ & 6494038 & $\begin{array}{l}\text { Monomers } \\
\text { - GPDM } \\
\text { Self-etching adhesive monomer } \\
\text {-Comonomers, mono, difunctional } \\
\text { methacrylate monomers } \\
\text { - Solvents water, acetone and ethanol } \\
\text {-Photo-initiator (CQ)-based } \\
\text { photoinitiator } \\
\text {-Fillers three nano-sized fillers } \\
\text { - Fluoride-releasing fillers - sodium, hexa- } \\
\text { fluorosilicate and ytterbium fluoride }\end{array}$ & $\begin{array}{l}\text { Kerr Italia Sri, Via } \\
\text { Passanti, } 332 \text {, Italy }\end{array}$ \\
\hline $\begin{array}{l}\text { Dentin Conditioner, } \\
\text { GC }\end{array}$ & 1711101 & $\begin{array}{l}\text { Polyacrylic Acid for dentin pretreatment, } 25 \% \\
\text { liquid. }\end{array}$ & $\begin{array}{l}\text { GC Corporation, } \\
\text { TOKYO, JAPAN. }\end{array}$ \\
\hline $\begin{array}{l}\text { Ethylenediamine tetra acetic } \\
\text { acid, EDTA, MD-Chelcream }\end{array}$ & MCH1712131 & $\begin{array}{l}\text { It is an aminopolycarboxylic acid and a colorless, } \\
\text { water-soluble solid } \\
\text { Base: is ethylenediaminetetraacetate. }\end{array}$ & $\begin{array}{l}\text { META BIOMED } \\
\text { COLTD, Korea. DL- } \\
147-11\end{array}$ \\
\hline $\begin{array}{l}\text { HERCULITE Classic, } \\
\text { Microhybride Composite }\end{array}$ & 5872762 & $\begin{array}{l}79 \% \text { inorganic filler (by weight) BIS-GMA, } \\
\text { TEGDMA, camphorquinone, amine, iron oxide } \\
\text { pigments, aluminum borosilicate glass, colloidal } \\
\text { silica }\end{array}$ & $\begin{array}{l}\text { Kerr Italia Sri, Via } \\
\text { Passanti,332, Italy }\end{array}$ \\
\hline
\end{tabular}

\section{Teeth preparation:}

Caries, crack free and periodontally compromised mandibular first molars $(n=32)$ were collected from oral surgery department, Faculty of Dentistry, Mansoura University. Extracted teeth were selected after patients' approval according to institutional guidelines. All molars were cleaned from both calculus and soft tissue remnants then stored in $0.1 \%$ thymol solution. ${ }^{22}$ Roots were roughened using the high speed contra-angle hand piece with No. 2 cylindrical diamond stone to enhance their fixation in the self-cured acrylic resin. 23,24 The selected molars were embedded in upright position inside metallic cylinders $(25.5 \mathrm{~mm}$ diameter and $25 \mathrm{~mm}$ length) using fast setting polyester acrylic resin (Acrostone, Egypt.) with their axis perpendicular to horizontal plane of upper surface of the cylinders. Teeth were fixed and centralized in metallic cylinders by using drilling machine (Drill press, model No. ZJ 4110). Each tooth crown was held inside the chuck of a drilling machine $2 \mathrm{~mm}$ away from cervical line of the teeth, while a metal cylinder filled with unset self-cured acrylic resin was fixed on the table of the drilling machine, so that when moving the chuck of the drilling machine downwards, roots of the tooth were centrally 
embedded into the acrylic resin inside the metal cylinder till complete setting of the acrylic resin..$^{25}$ The occlusal surface of each molar was sectioned using a thin sectioning saw (Isomet 1000, Buehler) held perpendicular to the long axis of the ring to standardize the surface area of prepared teeth. ${ }^{23}$ The teeth were prepared using a milling machine $(\mathrm{AB}$ machine tools) according to standardized criteria: 12-degree axial taper, 1-mm axial reduction, and occluso-gingival height of $4 \mathrm{~mm}$ measured from prepared finish line. ${ }^{23}$ Therefore, all molars were prepared with standardized surface area. ${ }^{26}$

\section{Resin-Based Composite (RBC) Specimen Preparation}

Composite cylinders were fabricated by addition technique in which layers of a micro-hybrid lightcuring composite (Herculite Classic -Kerr, Italia, shade A2) (2mm thickness) condensed into a split aluminum mould ( $8 \mathrm{~mm}$ in diameter and $4 \mathrm{~mm}$ high). Every layer was dried using light for $40 \mathrm{sec}$ (Astralis 7; Ivoclar Vivadent, Schaan, Liechtenstein; output monitored at $600 \mathrm{~mW} \mathrm{~cm}^{-2}$ ). The set composite was taken away from the mould, and light-curing repeated from all surfaces for additional $40 \mathrm{sec}$ each on the areas which covered with the metallic surface of the mould. ${ }^{11}$ RBC surfaces were sandblasted with $50 \mu \mathrm{m} \mathrm{Al} \mathrm{Al}_{2}$ for 10 seconds, using an intraoral air-abrasion device at a pressure of $87 \mathrm{psi}$ (Optiblast,Buffalo Dental Mfg Inc, New York, NY, USA), then specimens were cleaned using digital ultrasonic cleaner (Model: CD-4820, CODYSON, China, and Serial No: 04120122463). ${ }^{27}$

\section{Group Classification and Bonding Procedure}

Prepared teeth classified into four equal groups $(n=8)$ according to conditioning materials applied to prepared dentin surface before cementation of composite cylinders:

Group I: No further pretreatment (T-NT) control group. Prepared teeth surfaces were thoroughly cleaned according to manufacturer's recommendations of used self-adhesive resin cement.
Group II: Self-etching adhesive (T-SE) group. Teeth surfaces were prepared as in group I, and followed by application of Self-etching adhesive (OptiBond All-In-One) according to manufacturer's recommendations as following: dole out 2-3 drops of OptiBond adhesive material (Kerr, Italia) into a clean well. Using of brush apply abundant amount of material to the prepared dentin surface. Scrub the surface with a brushing motion for $20 \mathrm{sec}$. another layer of OptiBond added with a brushing motion for $20 \mathrm{sec}$., dry the adhesive gently for at least $5 \mathrm{sec}$, then curing with light for $10 \mathrm{sec}$.

Group III: Pretreatment using dentin conditioning agent (Polyacrylic acid) (T-PA) group. Prepared teeth surfaces were cleaned like group I, and followed by application of polyacrylic acid (GC Corporation, Tokyo, Japan) using microbrush for 20 $\mathrm{sec}$ then teeth were rinsed with water for $20 \mathrm{sec}$.

Group IV: Pretreatment using EDTA (T-ED) group. Teeth prepared like group I and then EDTA was applied (MD-ChelCream, META BIOMED, Korea) to prepared teeth using microbrush for 60 sec. The prepared teeth were then washed using water for $30 \mathrm{sec} .{ }^{11}$ Self-adhesive resin luting material (SuperCem, self-etch self-adhesive resin cement, DentKist) which is a dual-cure dental resin cement, was used according to the manufacturer's steps. Cement mix was extruded through a mixing tip and was applied over the abraded surface of composite cylinders. After that each composite cylinder was adjusted in the center of the prepared tooth surface. Initial light-curing of the cement for 10 sec was performed to accelerate its setting for easy removal of excess at the dentin discs margin; then light-curing was performed at the lateral surfaces of the bonded specimens (20 sec on each of the four surfaces, totaling $90 \mathrm{sec}$ of light activation) ${ }^{27}$ During the cementation procedure, a load of $500 \mathrm{~g}$ was used over the bonded specimens to standardize applied pressure. The specimens were stored at $37^{\circ} \mathrm{C}$ in distilled water for 24 hours, before shear 
bond strength measurement ${ }^{27}$ followed by thermal cycling between $5^{\circ} \mathrm{C}$ and $50^{\circ} \mathrm{C}$ in distilled water with a dwell time of 1 minute (Theromocycler, Robota, Alexandria, Egypt) for 10.000 cycles.

\section{Shear bond strength test (SBS)}

The universal testing machine (Instron Universal testing machine, model no. 3345, England) was used for shear bond strength measurement at across-head speed of $0.5 \mathrm{~mm} / \mathrm{min}$. using computer software Blue Hill Instron. (Fig.1). It was recorded in $\mathrm{MPa}$ and was obtained by dividing the imposed force $(\mathrm{N})$ at the time of fracture by the bonding surface area (approx. $20 \mathrm{~mm}^{2}$ ). Failed areas of the specimens were evaluated. Specimens were dehydrated using solutions of ethanol, air dried, fixed on metallic stubs, then covered by thin layer of gold (Sputter Coating Evaporator, SPI Module - Sputter Carbon / Gold Coater), and examined using a Scanning electron microscope (SEM) (JEOL JSM 6510 lv, Japan) at different magnifications. Modes of failure which were detected classified into four types: (A) Adhesive failure found between resin-dentin interface; (B) Mixed failure, in which adhesive

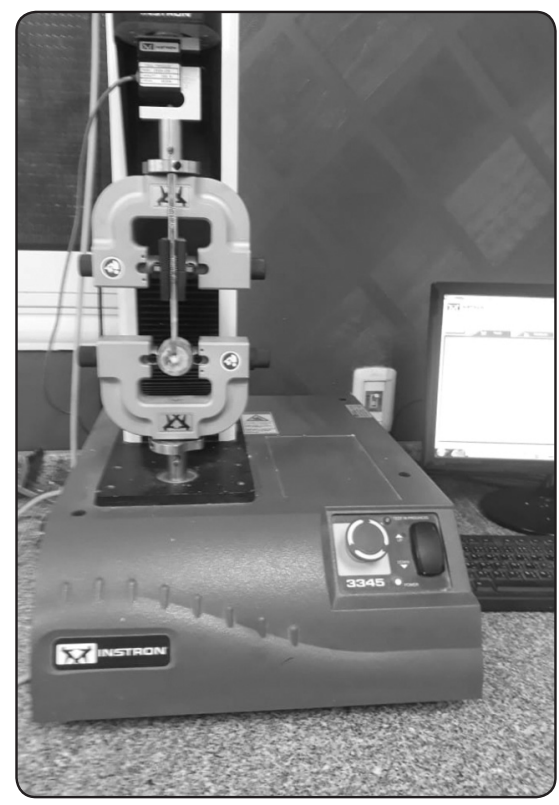

Fig. (1) Showing: Specimen fixed in universal testing machine for SBS test failure occurred with a thin layer of luting material found on the dentin surface; (C) Cohesive failure within luting material itself; (D) Partial cohesive failure in either dentin or resin. ${ }^{28}$

\section{RESULTS}

Statistical Package for Social Science software computer program (SPSS 22) was used for statistical analysis. One-way ANOVA followed by Posthoc Tukey tests were used for comparing data at ( $p=0.001$ ). It was found that the highest mean SBS (MPa) was reported for group T-SEB (3.9 MPa), while the lowest mean SBS value was observed for group T-NT (2 MPa). There was no statistically significant difference between group T-SEB (3.9 MPa) and group T-PA (3.3 MPa) ( $>>0.05)$. Also there was no statistically significant difference between the other two test groups (T-NT=2 MPa, T-ED=2.6 $\mathrm{MPa})(\mathrm{P}>0.05)$. On the other hand there was statistically significant difference between group T-NT (2 $\mathrm{MPa})$ and groups T-SE and T-PA groups $(\mathrm{P}<0.05)$.

Considering pretreatment methods of prepared teeth, the application of self-etching adhesive or polyacrylic acid significantly increased the mean shear bond strength of self-adhesive resin cement compared with other pretreatment methods. (Table $2,3)$

TABLE (2) Shear bond strength means and standard deviations (MPa) of all test groups bonded using self-adhesive resin cement

\begin{tabular}{|l|r|l|l|l|l|l|}
\hline & \multicolumn{3}{|c|}{ Mean \pm SD } & \multicolumn{3}{c|}{$\begin{array}{c}\text { Minimum/ } \\
\text { Maximum }\end{array}$} \\
\hline Group I (TNT) & 1.96 & \pm & 0.92 & 1.01 & - & 3.68 \\
\hline Group II (TSE) & 3.91 & \pm & 0.8 & 2.87 & - & 4.68 \\
\hline Group III (TPA) & 3.26 & \pm & 0.69 & 2.30 & - & 3.82 \\
\hline Group IV (TED) & 2.61 & \pm & 0.87 & 1.73 & - & 4.06 \\
\hline
\end{tabular}

Data expressed as mean $\pm S D$

SD: standard deviation

Test used: One way ANOVA 


\section{Scanning electron microscopy (SEM)}

The fracture patterns of the specimens were evaluated using SEM at 500x magnification as shown in (Table 4). Dentin surfaces treated using the self-etching adhesive (T-SE) demonstrated cohesive failure as the underlying dentin was covered completely with the resin cement. While polyacrylic acid group (T-PA) showed partial cohesive failure within the cement, loss of smear layer, wide opened dentinal tubules with comparatively some prominent resin tags were detected. On the other hand, in the EDTA treated group (T-ED), the resulted type of failure was mixed in which adhesive failure occurred between tooth and cement with very little remnants of resin cement adherent to the underlying dentin. In the T-NT group the observed failure mode was completely adhesive between dentin and resin cement as the tooth surface was free from any remnants of resin cement. (Fig. 2).

TABLE (3): Comparison among different groups according to shear stress at maximum load (Mpa)

\begin{tabular}{|c|c|c|c|c|c|}
\hline & $\begin{array}{c}\text { Group I } \\
\text { (TNT) }\end{array}$ & $\begin{array}{c}\text { Group II } \\
\text { (TSE) }\end{array}$ & $\begin{array}{c}\text { Group III } \\
\text { (TPA) }\end{array}$ & $\begin{array}{c}\text { Group IV } \\
\text { (TED) }\end{array}$ & P \\
\hline Maximum Load (MPa) & $1.96 \pm 0.92$ & $3.91 \pm 0.8$ & $3.26 \pm 0.69$ & 0.45 & $0.001^{*}$ \\
\hline P1 & & $0.001 *$ & $0.027 *$ & $0.027^{*}$ & \\
\hline P2 & & & 0.45 & 0.44 & \\
\hline
\end{tabular}

P:Probability *:significance $<0.05$

P1: significance relative to Group I (TNT)

P3: significance relative to Group IV (TED)

TABLE (4): Fracture patterns of tested groups

\begin{tabular}{|l|l|l|l|l|}
\hline Groups & CS & PC & MA & AD \\
\hline T-NT & 0 & 0 & 3 & 5 \\
\hline T-SE & 6 & 2 & 0 & 0 \\
\hline T-PA & 2 & 5 & 1 & 0 \\
\hline T-EDTA & 0 & 0 & 6 & 2 \\
\hline
\end{tabular}

CS, cohesive fracture; $P C$, partial cohesive; $M A$, mixed adhesive failure; $A D$, adhesive fracture at the interface.

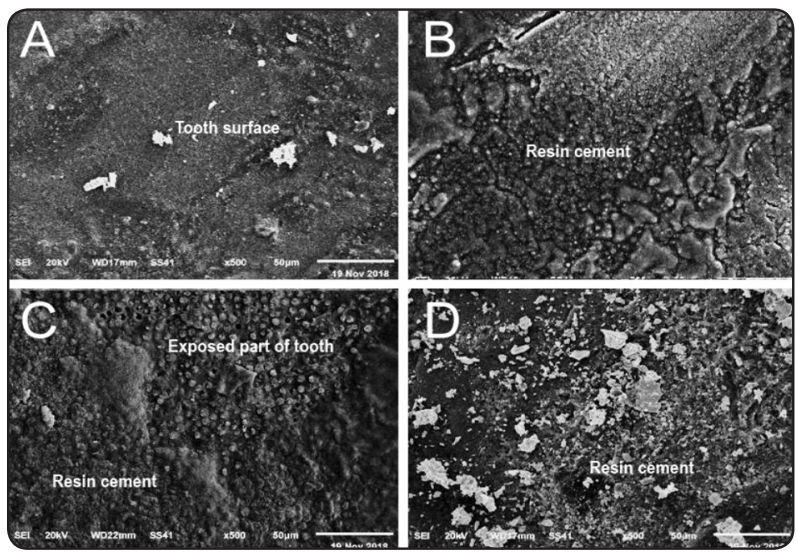

Fig. (2) Showing: Scanning electron microscopy (SEM) images of dentin at 500x magnification after the shear bond strength test A: T-NT group showed Adhesive failure. B: T-SE group showed cohesive failure. C: T-PA group showed partial cohesive failure. D: T-EDTA group showed mixed failure. 


\section{DISCUSSION}

The null hypothesis of the current research was refused as there was statistically significant difference in shear bond strength of pretreated dentin when different conditioning materials were used. The main target for increasing of bond strength of luting cements to prepared tooth structure is promoting sturdiness of the definitive restoration in terms of retention. ${ }^{28,}{ }^{29}$ In vitro studies should simulate clinical conditions, and therefore in this in vitro study specimens were subjected to thermal cycles. Multistep adhesive resin cements have some constraints to be used for cementation procedures, as these materials are expensive, time consuming for application, technique sensitive and require multiple, complicated bonding procedures., ${ }^{30,31-33}$ Therefore, self-adhesive resin cement was selected to be used in this in vitro study, as its bonding mechanism is based on demineralization and infiltration of dentin simultaneously at one time to form a hybrid layer through multifunctional monomers and acid groups included in their chemical composition..$^{34-37}$

The process of tooth preparation and dentin exposure, resulted in formation of dense smear layer. ${ }^{28}$ This layer is known as "any remnants, calcified in nature, formed during preparation or instrumentation of hard tooth structures..$^{38,39}$ Therewith, the smear layer has an inverse effect on any type of bonding mechanism formed between prepared tooth and the restorative material. ${ }^{39-41}$

Main problem of the smear layer, its weak bonding strengths so, many studies were performed to overcome this and found that, there were two ways can be used such as: removal of this layer completely before bonding procedure (etching with phosphoric acid), or application of bonding materials which penetrate behind the smear layer and incorporate it into the bonding layer (self-etching, such as self-adhesive resin cements and self-etch adhesive system) ${ }^{42}$ In another way, the presence of smear layer is not only cause for weak bond strength but it was found that there are some causes may led to the reduced capacity of the self-adhesive cements to diffuse and decalcify the underlying dentin effectively: (1) its high viscosity, which may rapidly increase as an acid-base reaction; (2) a neutralization effect which might occur through setting reaction, since these chemical reactions may cause elevation of $\mathrm{pH}$ level as a result of water and alkaline filler release. ${ }^{43}$

In the current study, the effect of chemical cleansing methods on the final bond strength were tested in term of shear forces, because shear stress tends to provide a better explanation of the forces capable of displacing indirect restorations intraorally when compared with tensile stress. ${ }^{44}$ On the other side, the shear bond test is considered a dependable and suitable method of accessing the bond strength of luting materials. ${ }^{45}$

The water is one of the composition of selfetching adhesive systems which required for prohibition of acidic monomers ionization and demineralization of hard dental structures. This component has an inverse effect because remainder water and hydrophilic solvent within the interfacial structure reduce bond strength. ${ }^{46,}{ }^{47}$ Against the previously mentioned information, the prepared tooth surface must be kept dry by air after application of optibond self-etch adhesive. However, due to simple procedure of its application clinically in the current study, the remnants of water and solvents were not removed and the produced structure at the interfacial area became more hydrophilic, ${ }^{\mathbf{4 8 , 4 9}}$ thereby showing it to be more susceptible to hydrolytic degradation. ${ }^{50}$ According to manufacture recommendation, Optibond all-in-one is supplied in a one-bottle, single-phase, self-etching adhesive system containing hydroxyethyl methacrylate (HEMA), capable of diffusion through the formed smear layer. Another active reaction could be that acidic monomer in Optibond improved its bond to dentin by chemical reaction between calcium 
ions in hydroxyapatite of tooth structure..$^{51}$ Another method used for pretreatment of prepared teeth was the application of dentin conditioning agent (polyacrylic acid). This acid showed effective role in this study as it enhanced cleaning and wetting of tooth substrates because of its influential action in removal of smear layer so, the dentinal tubules and intertubular dentin were opened and exposed.11, ${ }^{34,35}$ Therefore, the used self-adhesive resin cement penetrated opened dentinal tubules and resulted in formation of hybrid layer. Another important effect of polyacrylic acid that it removed the smear layer, exposed the collagen fibrils (0.5-1.0 micrometer), and improved the ionic interaction between the carboxyl groups of the acid and calcium ions on the hydroxyapatite. This action might result in activation of calcium ions from the dental structure that consequently incorporated into the cement leading to increased the chemical reaction between dental luting agents and dentin..$^{34-36}$ The outcomes of this study was in agreement with the other studies which showed that, pretreatment of dentin using polyacric acid significantly promoted bond strength of self-adhesive resin cement to dentin. ${ }^{11,34,35}$ Teeth surfaces which treated with the self-etching adhesive and polyacrylic acid showed cohesive and partial cohesive dentin fracture on etched surface. When the cement was bonded to dentin surface which treated with self-etching adhesive and polyacrylic acid, opened dentinal tubules and minimal prominent resin tag formation were observed. After etching of dentin using polyacrylic acid, cement penetration were detected on the intertubular dentin. These results were in agreement with Mazzitelli et al., (2010) ${ }^{11}$ who concluded that pretreatment of dentin using different conditioning materials facilitates cleaning of surfaces by smear layer removal, but the viscosity of the materials inhibits spread through prepared surface. Widening and opening of dentinal tubules allows resin tags formation, and water flow that may affect strength of bonding mechanism. Third method used for pretreatment of prepared dentin in this study was the application of EDTA. The calcium-chelating ability of EDTA resulted in minimal elimination of smear layer and smear plug without observed increase in surface irregularities. ${ }^{52}$ The shear bond strength of test specimens (T-ED) was significantly lower than the T-SE group. This mentioned result could be related to the restricted chelating action of EDTA as concluded in other study. ${ }^{53}$ In the EDTA-treated group, mixed adhesive failure between tooth and cement was detected, because when dentin surfaces were treated using EDTA, observed change of filamentous debris and voids within the cement layer were found. ${ }^{11}$ From the results of the current study, maximum bonding strength of adhesive resin cement was obtained from prepared teeth surfaces conditioned with selfetching adhesives and polyacrylic acid.

\section{CONCLUSION}

Within the conditions of the present study, the following conclusions can be drawn:

- Pretreatment of prepared teeth using self-etching adhesives and polyacrylic acid improved bond strength of self-adhesive resin cement to the prepared dentin.

- Conditioning of prepared dentin using EDTA did not enhance bond strength of self-adhesive resin cement.

\section{REFERENCES}

1- Grasso CA, Caluori DM, Goldstein GR, \& Hittelman E. In vivo evaluation of three cleansing techniques for prepared abutment teeth. J Prosthet Dent 2002; 88:437-441.

2- Hikita K, Van Meerbeek B, De Munck J, Ikeda T, Van Landuyt K, Maida T, Lambrechts P, \& Peumans M. Bonding effectiveness of adhesive luting agents to enamel and dentin. Dent Mater 2007; 23:71-80.

3- Luhrs AK, Gur S, Günay H, \& Geurtsen W. Shear bond strength of self-adhesive resins compared to resin cements with etch and rinse adhesives to enamel and dentin in vitro. Clin Oral Investig 2010; 14:193-199. 
4- Sarac s, Bulucu B, Sarac , YS, \& Kulunk S.The effect of dentin-cleaning agents on resin cement bond strength to dentin. J AM Dent Assoc 2008; 139: 751-758.

5- Macorra JC, Pradı́es G. Conventional and adhesive luting cements. Clin Oral Investig 2002; 6:198-204.

6- Breschi L, Mazzoni A, Ruggeri A, Cadenaro M, DiLenarda, \& De Stefano Dorigo E. Dental adhesion review: Aging and stability of the bonded interface Dent Mater 2008;24: 90-101.

7- Ferrancane JL, Stansbury JW, Burke FJT. Review Article: Self-adhesive resin cements - chemistry, properties and clinical considerations. J Oral Rehabil 2011; 38:295-314.

8- Mazzitelli C, Monticelli F, Osorio R, Casucci A, Toledano M, Ferrari M. Effect of simulated pulpal pressure on self-adhesive cements bonding to dentin. Dent Mter 2008; 24:1156-1163.

9- Monticelli F, Osorio R, Mazzitelli C, Ferrari M, Toledano M. Limited decalcification/diffusion of self-adhesive cements into dentin. J Dent Res 2008; 87: 974-979.

10- Al-Assaf K, Chakmakci M, Palaghias G, Karanika- Kouma A, Eliades G. Interfacial characteristics of adhesive luting resins and composites with dentine. Dent Mater 2007; 23:829-839.

11- Mazzitelli C, Monticelli F, Toledano M, Ferrari M, Osorio R. Dentin treatment effects on the bonding performance of self-adhesive resin cements. Eur J Oral Sci 2010; 118:8086.

12- Weiser F, Behr M. Self-Adhesive Resin Cements: A Clinical Review. J Prosthodont 2015; 24:100-108.

13- Manso AP, Carvalho RM. Dental Cements for Luting and Bonding Restorations: Self-Adhesive Resin Cements. Dent Clin North Am. 2017; 61:821-834.

14- Oliveira SS, Pugach MK, Hilton JF, Watanabe LG, Marshall SJ, \& Marshall GW Jr. The influence of the dentin smear layer on adhesion: a self-etching primer vs. a totaletch system. Dent Mater 2003; 19: 758-767.

15- De Munck J, Vargas M, Van LK, Hikita K, Lambrechts P, $\&$ Van MB. Bonding of an auto-adhesive luting material to enamel and dentin. Dent Mater 2004; 20: 963-971.

16- Tjaderhane L, Nascimento FD, Breschi L, Mazzoni A, Tersariol IL, GeraldeliS, et al. Strategies to prevent hydrolytic degradation of the hybrid layer-A review. Dent Mater 2013; 29:999-1011.
17- Ayad MF, Maghrabi AA, Saif RE, Garcia GF. Influence of tooth preparation burs on the roughness and bond strength of adhesives to human dentin surfaces. Am J Dent 2011; 24:176-182.

18- Poletto D, Poletto AC , Cavalaro A, Machado R , CosmeSilva $\mathrm{L}$,et al. Smear layer removal by different chemical solutions used with or without ultrasonic activation after post preparation. Restor Dent Endod. 2017; 42:324-331.

19- Behr M, Rosentritt M, Regnet T, Lang R, Handel G. Marginal adaptation in dentin of a self-adhesive universal resin cement compared with well-tried systems. Dent Mater 2004; 20:191-197.

20- Mine A, De Munck J, Cardoso MV, Van Landuyt KL, Poitevin A, Kuboki T, Yoshida Y, Suzuki K, Lambrechts P, Van Meerbeek B. Bonding effectiveness of two contemporary self-etch adhesives to enamel and dentin. J Dent 2009; 37: 872-883.

21- Sarr M, Mine A, De Munck J, Cardoso MV, Kane AW, Vreven J, Van Meerbeek B, Van Landuyt KL. Immediate bonding effectiveness of contemporary composite cements to dentin. Clin Oral Investig 2009; DOI: 10.1007/s00784009-0327-8.

22- Attia A. Influence of treatment modalities of prepared teeth on retention of cast metal copings bonded with self-adhesive resin cements. Quintessence Int. 2012; 43:73-81.

23- Johnson GH, Lepe X, Zhang H, Wataha JC. Retention of metal-ceramic crowns with contemporary dental cements. J Am Dent Assoc 2009; 140:1125-1136.

24- Zidan $\mathrm{O}$ and Ferguson GC. The retention of complete crowns prepared with three different tapers and luted with four different cements. J.Prosthet. Dent. 2003; 89:565-571.

25- Dawoud LEM. The effect of different occlusal convergency and luting cements on the retention of extra-coronal ceramic restoration. Master thesis. Mansoura University, Mansour, Egypt, 1999.

26- Madina MM, Ozcan M, Badawi MF. Effect of surface conditioning and taper angle on the retention of IPS e.max press crowns. J Prosthodont 2010; 19:200-204.

27- Santos MJMC, Bapoo H, Rizkalla AS, Santos GC. Effect of Dentin-cleaning Techniques on the Shear Bond Strength of Self-adhesive Resin Luting Cement to Dentin. Oper Dent 2011; 36-5: 512-520.

28- Lin J, Shinya A, Gomi H, Shinya A. Bonding of selfadhesive resin cements to enamel using different surface 
treatments: bond strength and etching pattern evaluations. J Dent Mater 2010; 29: 425-432.

29- Capa N, Ozkurt Z, Canpolat C, Kazazoglu E. Shear bond strength of luting agents to fixed prosthodontic restorative core materials. Aust Dent J 2009; 54:334-340.

30- Attia A, Abdelaziz KM, Freltag S, Kern M. Frcture load of composite resin and feldspathic all-ceramic CAD/CAM crowns. J Prosthet Dent 2006; 95:117-123.

31- Chaves CAL, de Melo RM, Passos SP, Camargo FP, Bottino MA, Balducci I. Bond strength durability of self-etching adhesives and resin cements to dentin. J Appl Oral Sci 2009; 17:155-160.

32- Zhang C, Degrange M. Shear bond strengths of self-adhesive luting resins fixing dentine to different restorative materials. J Biomater Sci Polym Ed 2010; 21:593-608.

33- Vlotti RG, Kasaz A, Pena CE, Alexandre RS, Arrais CA, Reis AF. Microtensile bond strength of new self-adhesive luting agents and conventional multistep systems. J Prosthet Dent 2009; 102:306-312.

34- Simões TC, Rubim MG, de Carvalho RV, de Sá ATG, Berger SB, Torres WAM. Effect of Polyacrylic Acid Conditioning on the Longevity of Bonding of Self - Adhesive Resin Cement to Dentin. J Health Sci 2018;20:100-105

35- Pavan S, dos Santos PH, Berger S, Bedran-Russo AK. The effect of dentin pretreatment on microtensile bond strength of self-adhhesive resin cements. J Prosthet Dent 2010; 104:258-264.

36- Brunzel S, Yang B, Wolfart S, Kern M. Tensile bond strength of a so-called self-adhesive luting resin cement to dentin. J Adhes Dent 2012; 12:143-150.

37- Cerqueira LAC, Costa AR, Spohr AM, Miyashita E, Miranzi BAS, et al. Effect of Dentin Preparation Mode on the Bond Strength Between Human Dentin and Different Resin Cements. Braz Dent J 2018; 29: 268-274

38- Gwinnett AJ. Quantitative contribution of resin infiltration/ hybridization to dentin bonding. Am J Dent 1993; 6: 7-9.

39- Ishioka S, Caputo AA. Interaction between the dentinal smear layer and composite bond strengths. J Prosthet Dent 1989; 61: 180-185.

40- Koibuchi H, Yasuda N, Nakabayashi N. Bonding to dentin with a self-etching primer: the effect of smear layers. Dent Mater 2001; 17: 122-126.

41- Van Meerbeek B, De Munck J, Mattar D, Van Landuyt K, Lambrechts P. Microtensile bond strengths of an etch \& rinse and self-etch adhesive to enamel and dentin as a function of surface treatment. Oper Dent 2003; 28: 647-660.

42- Van Meerbeek B, De Munck J, Yoshida Y, Inoue S, Vargas M, Vijay P, Van Landuyt K, Lambrechts P, Vanherle G. Buonocore memorial lecture. Adhesion to enamel and dentin: current status and future challenges. Oper Dent 2003; 28: 215-235.

43- Monticelli F, Osorio R, Mazzitelli C, Ferrari M, Toledano M. Limited decalcification/diffusion of self-adhesive cements into dentin. J Dent Res 2008; 87:974-979.

44- Kitasako Y, Burrow MF, Nikaido T, Harada N, Inokosh S, Yamada T, \& Takatsu T. Shear and tensile bond testing for resin cement evaluation. J Dent Mater. 1995; 11: 298-304.

45- Blixt M, Adamesaky E, Linden LA, Olden A, \& ArvidsonK. Bonding to densely sintered alumina surfaces: Effect of sandblasting and silica coating on shear bond strength of luting cements Int J of Prosthodont 2000; 13: 221-226.

46- Van Landuyt KL, Mine A, De Munck J, Countinho E, Peumans $\mathrm{M}$, et al. Technique sensitivity of water-free one-step adhesives. Dent Mater 2008; 24: 1258-1267.

47- Van Landuyt KL, Snauwaert J, Peumans M, De Munck J, Lambrechts P, Van Meerbeek B. The role of HEMA in one step self-etch adhesives. Dent Mater 2008; 24: 1412-1419.

48- Malacarne J, Carvalho RM, de Goes MF, Svizero N, Pashley DH, Tay FR, Yiu CK, Carrilho MR. Water sorption/ solubility of dental adhesive resins. Dent Mater 2006; 22: 973-980.

49- Hashimoto M, Ohno H, Kaga M, Endo K, Sano H, Oguchi H. In vivo degradation of resin-dentin bonds in humans over 1 to 3 years. J Dent Res 2000; 79: 1385-1391.

50- De Munck J, Van Landuyt K, Peumans M, Poitevin A, Lambrechts P, Braem M, Van Meerbeek B. A critical review of the durability of adhesion to tooth tissue: methods and results. J Dent Res 2005; 84: 118-132.

51- El-Guindy J, Selim M, El-Agroudi M. Alternative pretreatment modalities with a self-adhesive system to promote dentin/alloy shear bond strength. J Prosthodont 2010; 19:205-211.

52- Smith JB, Loushine RJ, Weller RN, Rueggeberg FA, Whitford GM, Pashley DH, Tay FR. Metrologic evaluation of the surface of white MTA after the use of two endodontic irrigants. J Endod 2007; 33: 463-467.

53- Kusunoki M, Itoh K, Oikawa M, Hishamitsu H. Measurement of shear bond strength to intact dentin. Dent Mater J. 2010; 29:199-205. 